\title{
ANTIBACTERIAL AND PHARMACOKINETIC PROPERTIES OF M14659, A NEW INJECTABLE SEMISYNTHETIC CEPHALOSPORIN
}

\author{
Hidenori Mochizuki, Yoshihiro Oikawa, Hidehiko Yamada, \\ Satoshi Kusakabe, Tomoko Shilhara, Kimihiro Murakami, \\ Kazuo Kato, Junzo Ishiguro and Hiroshi Kosuzume
}

Fuji Central Research Laboratory, Mochida Pharmaceutical Co., Ltd., Gotemba, Shizuoka 412, Japan

(Received for publication July 3, 1987)

\begin{abstract}
In vitro and in vivo antibacterial activities and pharmacokinetics of M14659 were investigated. In vitro activity of M14659 was superior to that of ceftazidime against Staphylococcus aureus. Against Gram-negative bacteria except Pseudomonas aeruginosa, its activity was almost equal to that of ceftazidime. M14659 was more active against $P$. aeruginosa including multi-drug resistant strains than cefsulodin, cefoperazone or ceftazidime. Affinities of M14659 for penicillin-binding proteins (PBPs) of Escherichia coli and P. aeruginosa were 2 to 14 times higher for PBP-1A and PBP-1B than found for ceftazidime, and almost the same for PBP-3. In vivo activity of M14659 against $S$. aureus was superior to that of cefamandole, cefotaxime or ceftazidime. Against Gram-negative bacteria including $P$. aeruginosa, M14659 was 2 to 220 times more active than cefotaxime or ceftazidime. Plasma half-life of M14659 in mice was about 3 times longer than that of ceftazidime. M14659 administered intravenously to mice was mainly excreted in urine without metabolism, and its recovery rate was almost equal to that of ceftazidime.
\end{abstract}

In recent years a number of cephalosporins with enhanced activity against Gram-negative bacteria has been developed ${ }^{1)}$. Among them, ceftazidime is the most potent agent against $P_{\text {seudomonas }}$ aeruginos $a^{1,2)}$, and is often used alone in pseudomonal infections as an alternative to aminoglycosides ${ }^{22}$. However, ceftazidime has a notable weakness against Staphylococcus aureus ${ }^{12}$, and ceftazidime-resistant strains of $P$. aeruginosa have already emerged ${ }^{3,4}$. Thus, there is continued interest in the development of new cephalosporins which have a balanced spectrum of activity and more potent antipseudomonal activity than ceftazidime. M14659 is a new injectable semisynthetic cephalosporin antibiotic which has a (2-carboxy-5-methyl-s-triazolo[1,5-a]pyrimidine-7-yl)thiomethyl group at the 3 position of the cephalosporin nucleus and a 2-(2-amino-4-thiazoly1)-2-[Z-[(S)-carboxy(3,4-dihydroxyphenyl)methyl]oxyimino]acetamido group at its 7 position (compound 3 in Scheme 1). In preliminary comparisons, M14659 was very active against Gram-positive and Gram-negative bacteria, and showed more potent antibacterial activities than ceftazidime against $S$. aureus and $P$. aeruginosa including ceftazidime-resistant strains ${ }^{5)}$. In the present report, we further investigated in vitro properties, in vivo antibacterial activities and pharmacokinetics in mice of M14659 in comparison with those of ceftazidime.

\section{Materials and Methods}

Antibiotics

M14659 was synthesized as described in Experimental. Nitrocefin was synthesized at Fuji Central Research Laboratory, Mochida Pharmaceutical Co., Ltd., Shizuoka, Japan. The other antibiotics 
Scheme 1.<smiles>CC(=O)Oc1ccc(C(O/N=C(\C(=O)O)c2csc(Nc3ccccc3)n2)C(=O)O)cc1OC(C)=O</smiles>

Compound 1<smiles>[Y]C(CC)CCC</smiles><smiles>CC(=O)Oc1ccc(C(=O)O/N=C(\C(=O)O)c2csc(Nc3ccccc3)n2)cc1OC(=O)C1C(=O)N2C(C(=O)Oc3ccccc3)=C(CSc3cc(C)nc4nc(C(=O)OC(c5ccccc5)c5ccccc5)nn34)CSC12</smiles>

Compound 2<smiles>COc1ccc(C(=O)O/N=C(\C(=O)O)c2csc(N)n2)cc1OC(=O)NC1C(=O)N2C(C(=O)O)=C(CSc3cc(C)nc4nc(C(=O)O)nn34)CSC1N2C(=O)O</smiles>

M14659 (compound 3)<smiles>CC1=C(C(=O)OCc2ccccc2)N2C(=O)C(N)C2SC1</smiles> 
were commercially obtained from the manufactures as follows: Cefazolin, Fujisawa Pharmaceutical Co., Ltd., Osaka, Japan; cefmetazole, Sankyo Co., Ltd., Tokyo, Japan; cephaloridine, cefamandole, Shionogi \& Co., Ltd., Osaka, Japan; cefsulodin, Takeda Chemical Industries, Ltd., Osaka, Japan; cefotaxime, Chugai Pharmaceutical Co., Ltd., Tokyo, Japan; cefoperazone, Toyama Chemical Co., Ltd., Toyama, Japan; ceftazidime, Glaxo Inc., London, England.

\section{Bacterial Strains}

Standard strains of bacteria were obtained from Institute for Fermentation, Osaka, Japan. A total of 279 bacterial isolates including $\beta$-lactamase producing resistant strains of $P$. aeruginosa were recent clinical isolates collected from several hospitals in Japan.

\section{Determination of MIC}

MIC values were determined by the 2-fold agar dilution method with Mueller-Hinton medium (Difco Laboratories, Detroit, U.S.A.). Bacteria were cultured overnight at $37^{\circ} \mathrm{C}$, and diluted to a final inoculum of $10^{\circ} \mathrm{cfu} / \mathrm{ml}$ with Mueller-Hinton broth (MHB, Difco Laboratories, Detroit, U.S.A.). $5 \mu \mathrm{l}$ of the diluted broth culture was inoculated onto the agar plates containing antibiotics with a Microplanter (Sakuma Seisakusho, Ltd., Tokyo, Japan) to give a final inoculum of $5 \times 10^{3} \mathrm{cfu}$ and bacterial growth was observed 18 hours after the inoculation at $37^{\circ} \mathrm{C}$. The MIC was defined as the lowest antibiotic concentration which prevented visible bacterial growth.

\section{Determination of MBC}

MBC values were determined with 18 -hour broth cultures of bacteria in MHB. Bacteria were cultured overnight at $37^{\circ} \mathrm{C}$, and diluted to $2 \times 10^{4} \mathrm{cfu} / \mathrm{ml}$ with MHB. Test tubes containing $1 \mathrm{ml}$ of the culture dilutions and $1 \mathrm{ml}$ of serial 2-fold dilutions of antibiotics were incubated at $37^{\circ} \mathrm{C}$ for 18 hours. After incubation, the broth dilution MIC was determined as the lowest antibiotic concentration inhibiting visible bacterial growth. $5 \mu \mathrm{l}$ from each tube inhibiting visible bacterial growth was inoculated on agar plates with a Microplanter. After 18 hours of incubation at $37^{\circ} \mathrm{C}, \mathrm{MBC}$ was determined as the lowest antibiotic concentration which prevented bacterial growth on the agar plate.

\section{$\beta$-Lactamases}

$\beta$-Lactamases obtained from $P$. aeruginosa $3 \mathrm{R}, 12 \mathrm{R}$ and $16 \mathrm{R}$ were prepared according to the method of MiNAMI et al. ${ }^{6}$. Bacteria were cultured at a concentration of $5 \times 10^{8} \mathrm{cfu} / \mathrm{ml}$ in MHB at $37^{\circ} \mathrm{C}$ for 4 hours, and collected by centrifugation at $7,500 \times g$ for 10 minutes. Then, the bacteria were sonicated and centrifuged at $13,000 \times g$ for 30 minutes. The resulting supernatant was used as a crude enzyme solution. $\beta$-Lactamase obtained from Enterobacter cloacae was purchased from Sigma Chemical Company, St. Louis, U.S.A. $\beta$-Lactamases obtained from Citrobacter freundii GN 7391 and Proteus vulgaris 1427 were kindly provided from Dr. M. TAJIMA.

\section{Assay of $\beta$-Lactamase}

$\beta$-Lactamase assay was carried out by the spectrophotometric method of Ross and O'CALLAGHAN ${ }^{7)}$. The decrease in absorbance of the substrate at an appropriate wavelength was measured in a temperature-controlled spectrophotometer (Hitachi Model 220A, Tokyo, Japan) at $30^{\circ} \mathrm{C}$. The absorption maxima of the cephalosporins as follows: Cephaloridine, $260 \mathrm{~nm}$; nitrocefin, $510 \mathrm{~nm}$; cefotaxime, $264 \mathrm{~nm}$; ceftazidime, $257 \mathrm{~nm}$; M14659, $298 \mathrm{~nm}$. The Vmax and $\mathrm{Km}$ were calculated using the Michaelis-Menten equation. For the determination of $K i$ by Dixon plots, rates of hydrolysis of 20 and $40 \mu \mathrm{M}$ nitrocefin were determined in the presence of various concentrations of the inhibitor with an autoanalyzer (COBAS FARA, F. Hoffmann-La Roche \& Co., Basel, Switzerland). In these experiments enzyme was preincubated with the inhibitor for 5 minutes before the addition of nitrocefin.

\section{Affinity for Penicillin-binding Proteins (PBPs)}

Membrane fractions were prepared from $E$. coli NIHJ JC-2 and $P$. aeruginosa IFO 3445 exponentially grown in Antibiotic Medium No. 3 (Difco Laboratories, Detroit, U.S.A.) according to the method of SPRATT ${ }^{8}$, and suspended at $15 \mathrm{mg} / \mathrm{ml}$ in $0.05 \mathrm{M}$ sodium phosphate buffer. $30 \mu \mathrm{l}$ of the membrane preparation was preincubated with $3 \mu$ l of either $0.05 \mathrm{M}$ phosphate buffer or dilutions of nonradioactive antibiotics for 10 minutes at $30^{\circ} \mathrm{C} .3 \mu 1$ of $\left[{ }^{14} \mathrm{C}\right]$ benzylpenicillin $(162 \mu \mathrm{Ci} / \mathrm{ml}$, specific activity; 
$54 \mathrm{mCi} / \mathrm{mmol}$, Amersham International plc, England) was added and incubated for further 10 minutes at $30^{\circ} \mathrm{C}$. The binding was terminated by the addition of $2 \mu \mathrm{l}$ of $15 \%(\mathrm{w} / \mathrm{v})$ Sarkosyl solution containing $45 \mathrm{mg}$ unlabeled benzylpenicillin per ml (Banyu Pharmaceutical Co., Ltd., Tokyo, Japan). After the suspension was allowed to stand for 20 minutes at $20^{\circ} \mathrm{C}$, the inner membrane fraction (Sarkosylsoluble fraction) was obtained by centrifugation at $14,000 \times g$ for 30 minutes at $20^{\circ} \mathrm{C}$. The fraction was mixed with $15 \mu \mathrm{l}$ of $0.2 \mathrm{M}$ Tris- $\mathrm{HCl}$ buffer ( $\mathrm{pH} 6.8$ ) containing sodium dodecyl sulfate $3 \%(\mathrm{w} / \mathrm{v}$ ), glycerol $30 \%(\mathrm{w} / \mathrm{v})$, bromophenol blue $0.002 \%(\mathrm{w} / \mathrm{v})$, and $4.5 \mu 1$ of 2-mercaptoethanol, and heated in a boiling water bath for 2 minutes. $10 \mu \mathrm{l}$ of the solution was then subjected to slab gel electrophoresis according to the method of NoGuchi et al. ${ }^{9}$. After electrophoresis, the gel was fixed in $300 \mathrm{ml}$ of $30 \%$ methanol $-10 \%$ acetic acid for 15 hours at room temp, and washed 5 times for $0.5 \sim 1$ hour each with $300 \mathrm{ml}$ of the same solution. The gel was soaked in $300 \mathrm{ml}$ of Enlightning (New England Nuclear, U.S.A.) with gentle shaking for 45 minutes, and dried in vacuo on Whatman No. 3 MM paper. A fluorogram was prepared by exposing the gel to X-ray film (Kodak X-Omat AR film) at $-80^{\circ} \mathrm{C}$ for $3 \sim 4$ weeks. The concentrations of antibiotics required for $50 \%$ binding inhibition of ${ }^{14} \mathrm{C}$-labeled benzylpenicillin to PBPs $\left(\mathrm{IC}_{50} \mathrm{~s}\right)$ were determined with a Densitometer (Model CS-900; Shimadzu Corp., Kyoto, Japan) from the fluorograms.

Determination of In Vivo Activity

In vivo antibacterial activities of antibiotics were studied in 4-week-old male ICR strain mice (Shizuoka Laboratory Animal Center, Shizuoka, Japan). Ten mice per group were intraperitoneally infected with 2 to 8 times the $50 \%$ lethal doses of the bacteria suspended in $0.2 \mathrm{ml}$ of sterile saline containing 5\% gastric mucin (Nakarai Chemicals, Ltd., Tokyo, Japan). Challenge doses ranged from $7 \times 10^{4}$ to $3 \times 10^{8} \mathrm{cfu}$ per mouse. Appropriate doses of antibiotics were administered intravenously 1 hour after infection. The $50 \%$ effective dose $\left(\mathrm{ED}_{50}\right)$ was calculated by the Litchfield-Wilcoxon method $^{10)}$ from the number of mice surviving 7 days after infection.

Serum Protein Binding

One volume of an antibiotic solution $(1,000 \mu \mathrm{g} / \mathrm{ml})$ in $1 / 15 \mathrm{M}$ phosphate buffer solution $(\mathrm{pH} 7.0)$ was added to 9 volumes of fresh sera of mice, rats and humans. The reaction mixture was incubated at $37^{\circ} \mathrm{C}$ for 1 hour with gentle shaking and then subjected to centrifugal ultrafiltration with a MPS-3 device (Amicon Corp., Denvers, U.S.A.). The protein-free ultrafiltrate, containing the unbound antibiotic, was microbiologically assayed by using $P$. vulgaris GN 5298 as a test organism.

\section{Plasma Concentrations of Antibiotics}

Antibiotics dissolved in sterile physiological saline just before use, were administered intravenously to ICR strain mice at a dose of $20 \mathrm{mg} / \mathrm{kg}$. Blood samples of mice in groups of five were withdrawn from the heart with heparinized syringes at $1,2.5,5,10,20,30,40,60,120$ and 240 minutes after administration, respectively. Plasma was separated from these heparinized blood samples by centrifuging at $1,400 \times g$ at $4^{\circ} \mathrm{C}$, and $50 \mu 1$ of $0.14 \mathrm{~N}$ hydrochloric acid was added to a portion of $100 \mu 1$ of each plasma sample of M14659 for HPLC analysis. Plasma samples were stored at $-80^{\circ} \mathrm{C}$ until analyzed. Antibiotic concentration of the plasma was determined by bioassay using $P$. vulgaris $\mathrm{GN}$ 5298 as a test organism. Plasma concentrations of M14659 were also determined by HPLC.

\section{Urinary Concentrations of Antibiotics}

Antibiotics dissolved in sterile physiological saline just before use, were administered intravenously to two ICR strain mice per metabolic cage at a dose of $20 \mathrm{mg} / \mathrm{kg}$. Urine samples from five cages were collected at 0 to 3,3 to 6,6 to 9 , and 9 to 24 hours after administration, and $400 \mu 1$ of $0.5 \mathrm{~m}$ acetate buffer ( $\mathrm{pH} 4.0$ ) was added to a portion of $100 \mu 1$ of each urine sample of M14659 for HPLC analysis. Urine samples were stored at $-80^{\circ} \mathrm{C}$ until analyzed. Antibiotic concentration of the urine was determined as described above.

\section{HPLC Analysis}

$50 \mu \mathrm{l}$ of distilled water was added to $150 \mu \mathrm{l}$ of the plasma sample containing $0.14 \mathrm{~N}$ hydrochloric acid. After centrifugation, supernatant was filtered with Millipore Column Guard $(0.45 \mu \mathrm{m}$, Nihon 
Millipore Kogyo K.K.), and the filtrate was analyzed by HPLC. Urine samples were also analyzed by HPLC after centrifugation and filtration with the membrane. A standard curve was determined by using standard antibiotics dissolved in normal mouse plasma or urine (concentrations and \% recovery of standards: $0.5 \sim 200 \mu \mathrm{g} / \mathrm{ml}$ and $97 \%$ for plasma, $20 \sim 1,000 \mu \mathrm{g} / \mathrm{ml}$ and $96 \%$ for urine, respectively) and it was confirmed that there were no peaks having the same retention time as M14659 in normal mouse plasma or urine at the same time. The correlation coefficient of the standard curve was $>0.999$. The lower limits of HPLC sensitivity were $0.5 \mu \mathrm{g} / \mathrm{ml}$ for plasma, and $20 \mu \mathrm{g} / \mathrm{ml}$ for urine. In this HPLC analysis internal or external standards were not used. The equipments and conditions for HPLC were as follows:

Pump: TRI ROTOR-VI (Japan Spectroscopic Co.), sample injector: Model 7125 (Reodine Co.), UV detector: UVIDEC-100-VI (Japan Spectroscopic Co.), recorder: Chromatograph processor Model 8000A (System Instruments Corp.), column: TSK-GEL ODS-120A, $4 \times 250 \mathrm{~mm}$ (Toyo So Co.), mobile phase for plasma: Ammonium phosphate buffer (100 mM, pH 7.0) - acetonitrile (91.5:8.5), mobile phase for urine: Ammonium phosphate buffer (10 mM, pH 7.0) - acetonitrile $(94.0: 6.0)$, flow rate: $1.0 \mathrm{ml} / \mathrm{minute}$, wave length: $300 \mathrm{~nm}$, injection volume: $20 \mu \mathrm{l}$ (plasma), $40 \mu \mathrm{l}$ (urine).

\section{Pharmacokinetic Analysis}

The two-compartment model was used for pharmacokinetic analysis of M14659, and the onecompartment model for ceftazidime. The plasma half-lives $\left(T_{1 / 2}(\alpha)\right.$ and $\left.T_{1 / 2}(\beta)\right)$, the total body clearance $\left(\mathrm{CL}_{\text {tot }}\right)$, and the area under the plasma concentration versus time curve extrapolated to time infinity (AUC) were calculated by means of residual method and the following equations:

$$
\mathrm{T}_{1 / 2}(\alpha)=0.693 / \mathrm{k} \alpha, \quad \mathrm{T}_{1 / 2}(\beta)=0.693 / \mathrm{k} \beta, \quad \mathrm{CL}_{\mathrm{tot}}=\mathrm{D} / \mathrm{AUC}, \quad \mathrm{AUC}=\mathrm{C}_{0} / \mathrm{k} \beta,
$$

where $D$ represents the dose, $C_{0}$ is the extrapolated initial plasma concentration, and $k \beta$ is the elimination rate constant.

\section{Results}

\section{Antibacterial Spectrum and In Vitro Activity of M14659}

M14659 is a potent, broad-spectrum cephalosporin, equally active on a weight basis against $S$. aureus and $P$. aeruginosa at concentrations in the range 0.20 to $3.13 \mu \mathrm{g} / \mathrm{ml}$. Enterobacteriaceae were susceptible to very low concentrations of $\mathrm{M} 14659 ; \mathrm{MIC}_{30}$ values were in the range 0.10 to $1.56 \mu \mathrm{g} / \mathrm{ml}$ for selected and clinical isolates (Tables 1 and 2).

M14659 has excellent anti-pseudomonal activity $\left(\mathrm{MIC}_{90} \quad 0.20 \mu \mathrm{g} / \mathrm{ml}\right)$. The range of MICs was narrow for clinical isolates and suggests that the cephalosporin has considerable potential for use in pseudomonal infections. In comparative studies, M14659 was shown to be considerably more active than cefsulodin or cefoperazone in terms of $\mathrm{MIC}_{90}$. Ceftazidime was active at comparable concentrations against some strains but M14659 had greater activity against some ceftazidime-resistant isolates. This property was further demonstrated for three $\beta$-lactamase producing $P$. aeruginosa strains (Table 3). M14659 retained its activity, whereas cefsulodin, cefoperazone, cefotaxime and ceftazidime were inactive against these isolates.

M14659 has good activity against S. aureus and Staphylococcus epidermidis; $\mathrm{MIC}_{90} 6.25 \mu \mathrm{g} / \mathrm{ml}$ for clinical isolates. This is less active on a weight basis than cefamandole but M14659 is more active in vitro than ceftazidime. All of the cephalosporins were inactive against methicillin-resistant strains.

The in vitro activity of M14659 against Enterobacteriaceae is typical of aminothiazolyl cephalosporins and in comparative studies, M14659 was shown to be as effective as cefotaxime or ceftazidime. Against Enterobacter strains, M14659 was effective against 46 isolates over a narrow concentration range, 0.02 to $1.56 \mu \mathrm{g} / \mathrm{ml}$. Both cefotaxime and ceftazidime were inactive to some of these isolates 
Table 1. Antibacterial spectra of M14659 and other cephalosporins against standard strains.

\begin{tabular}{|c|c|c|c|c|c|c|}
\hline \multirow{2}{*}{ Organism } & \multicolumn{6}{|c|}{$\operatorname{MIC}(\mu \mathrm{g} / \mathrm{ml})$} \\
\hline & M14659 & Cefazolin & Cefmetazole & Cefamandole & Cefotaxime & Ceftazidime \\
\hline Micrococcus luteus IFO 12708 & 0.78 & 0.78 & 0.20 & 0.05 & $<0.05$ & 0.39 \\
\hline Staphylococcus aureus $209 \mathrm{P}$ & 3.13 & 0.39 & 0.78 & 0.39 & 3.13 & 12.5 \\
\hline S. aureus NIHJ IID & 0.78 & 0.10 & 0.39 & 0.10 & 0.78 & 3.13 \\
\hline S. aureus Smith & 0.78 & 0.10 & 0.39 & 0.20 & 1.56 & 6.25 \\
\hline S. epidermidis IFO 3762 & 1.56 & 0.20 & 0.78 & 0.20 & 0.78 & 6.25 \\
\hline S. epidermidis IFO 12993 & 3.13 & 0.39 & 1.56 & 0.39 & 0.78 & 6.25 \\
\hline S. epidermidis IFO 13889 & 12.5 & 0.39 & 1.56 & 0.39 & 3.13 & 12.5 \\
\hline Enterococcus faecalis IFO 12964 & 50 & 25 & $>100$ & 50 & $>100$ & $>100$ \\
\hline E. faecalis IFO 12966 & $>100$ & 50 & $>100$ & 50 & $>100$ & $>100$ \\
\hline E. faecalis IFO 12969 & 100 & 50 & $>100$ & 50 & $>100$ & $>100$ \\
\hline E. faecium IFO 12367 & $>100$ & $>100$ & $>100$ & $>100$ & $>100$ & $>100$ \\
\hline Bacillus subtilis ATCC 6633 & 12.5 & 0.10 & 0.39 & 0.05 & 0.78 & 6.25 \\
\hline B. subtilis NIHJ PCI 219 & 6.25 & 0.20 & 0.78 & 3.13 & 1.56 & 6.25 \\
\hline Escherichia coli NIHJ JC-2 & 0.20 & 1.56 & 0.78 & 1.56 & 0.10 & 0.39 \\
\hline E. coli IFO 13168 & 0.05 & 1.56 & 0.78 & 0.20 & $<0.05$ & 0.05 \\
\hline Salmonella enteritidis IFO 3313 & $<0.05$ & 3.13 & 0.39 & 0.39 & 0.10 & 0.10 \\
\hline Citrobacter freundii IFO 12681 & 0.78 & 25 & 25 & 6.25 & 0.78 & 0.78 \\
\hline Klebsiella pneumoniae IFO 3317 & $<0.05$ & 0.78 & 0.39 & 0.10 & $<0.05$ & 0.05 \\
\hline K. pneumoniae FDA PCI 602 & $<0.05$ & 0.78 & 0.39 & 0.20 & $<0.05$ & 0.10 \\
\hline Enterobacter aerogenes IFO 13534 & $<0.05$ & 25 & $>100$ & 1.56 & 0.10 & 0.39 \\
\hline Serratia marcescens IFO 3736 & 0.05 & $>100$ & 1.56 & 1.56 & 0.10 & $<0.05$ \\
\hline S. marcescens IFO 3759 & 0.05 & $>100$ & 6.25 & 25 & 0.20 & 0.05 \\
\hline S. marcescens IFO 12648 & 0.78 & $>100$ & 6.25 & 50 & 0.20 & 0.10 \\
\hline Morganella morganii IFO 3848 & 0.39 & 0.78 & 0.78 & 0.78 & 0.05 & 0.39 \\
\hline Proteus mirabilis IFO 3849 & $<0.05$ & 6.25 & 3.13 & 1.56 & 0.05 & 0.05 \\
\hline P. vulgaris IID HX-19 & 0.05 & 12.5 & 1.56 & 0.39 & $<0.05$ & $<0.05$ \\
\hline P. vulgaris GN 5298 & 0.20 & 100 & 1.56 & 25 & $<0.05$ & 0.05 \\
\hline Vibrio parahaemolyticus IFO 12711 & 100 & 25 & 6.25 & 25 & 50 & 100 \\
\hline Acinetobacter calcoaceticus IFO 12552 & 6.25 & $>100$ & 100 & 100 & 12.5 & 6.25 \\
\hline Pseudomonas aeruginosa IFO 3445 & 1.56 & $>100$ & $>100$ & $>100$ & 12.5 & 1.56 \\
\hline$P$. aeruginosa No. 13 & 1.56 & $>100$ & $>100$ & $>100$ & 12.5 & 1.56 \\
\hline$P$. aeruginosa No. 19 & 0.20 & $>100$ & $>100$ & $>100$ & 25 & 3.13 \\
\hline Flavobacterium meningosepticum IFO 12535 & $>100$ & $>100$ & 12.5 & $>100$ & 25 & $>100$ \\
\hline
\end{tabular}


Table 2. In vitro antibacterial activities of M14659 and other cephalosporins against clinical isolates.

\begin{tabular}{|c|c|c|c|c|}
\hline \multirow{2}{*}{ Organism (No.) } & \multirow{2}{*}{ Antibiotic } & \multicolumn{3}{|c|}{$\operatorname{MIC}(\mu \mathrm{g} / \mathrm{ml})^{\mathrm{g}}$} \\
\hline & & $50 \%$ & $90 \%$ & Range \\
\hline \multirow[t]{3}{*}{ Staphylococcus aureus (14) } & M14659 & 1.56 & 6.25 & $1.56 \sim 50$ \\
\hline & Cefamandole & 0.78 & 0.78 & $0.39 \sim 50$ \\
\hline & Ceftazidime & 6.25 & 12.5 & $6.25 \sim>100$ \\
\hline \multirow[t]{3}{*}{$\operatorname{MRSA}^{\mathrm{b}}(15)$} & M14659 & 25 & $>100$ & $6.25 \sim>100$ \\
\hline & Cefamandole & 12.5 & 25 & $3.13 \sim 50$ \\
\hline & Ceftazidime & 100 & $>100$ & $12.5 \sim>100$ \\
\hline \multirow[t]{3}{*}{ Escherichia coli (63) } & M14659 & 0.10 & 0.39 & $0.012 \sim 6.25$ \\
\hline & Cefotaxime & 0.05 & 0.10 & $0.012 \sim 0.39$ \\
\hline & Ceftazidime & 0.10 & 0.20 & $0.024 \sim 0.78$ \\
\hline \multirow[t]{3}{*}{ Klebsiella sp. (50) } & M14659 & 0.05 & 0.39 & $0.012 \sim 0.78$ \\
\hline & Cefotaxime & 0.024 & 0.05 & $0.012 \sim 0.20$ \\
\hline & Ceftazidime & 0.10 & 0.20 & $0.024 \sim 0.39$ \\
\hline \multirow[t]{3}{*}{ Serratia sp. (10) } & M14659 & 0.78 & 0.78 & $0.39 \sim 3.13$ \\
\hline & Cefotaxime & 0.78 & 0.78 & $0.20 \sim 1.56$ \\
\hline & Ceftazidime & 0.10 & 0.20 & $0.10 \sim 0.78$ \\
\hline \multirow[t]{3}{*}{ Enterobacter sp. (46) } & M14659 & 0.39 & 1.56 & $0.024 \sim 1.56$ \\
\hline & Cefotaxime & 0.10 & 3.13 & $\leq 0.006 \sim 100$ \\
\hline & Ceftazidime & 0.20 & 0.39 & $0.024 \sim 50$ \\
\hline \multirow[t]{3}{*}{ Citrobacter sp. (10) } & M14659 & 0.20 & 1.56 & $0.024 \sim 1.56$ \\
\hline & Cefotaxime & 0.10 & 0.39 & $0.05 \sim 6.25$ \\
\hline & Ceftazidime & 0.20 & 0.20 & $0.05 \sim 12.5$ \\
\hline \multirow[t]{3}{*}{ Indole-positive Proteus sp. (6) } & M14659 & 0.10 & 0.20 & $0.024 \sim 0.20$ \\
\hline & Cefotaxime & 0.05 & 0.20 & $\leq 0.006 \sim 0.20$ \\
\hline & Ceftazidime & 0.05 & 0.20 & $0.05 \sim 0.20$ \\
\hline \multirow[t]{3}{*}{ Indole-negative Proteus sp. (15) } & M14659 & 0.012 & 0.10 & $\leq 0.006 \sim 0.10$ \\
\hline & Cefotaxime & 0.024 & 0.024 & $\leq 0.006 \sim 0.024$ \\
\hline & Ceftazidime & 0.05 & 0.05 & $\leq 0.006 \sim 0.05$ \\
\hline \multirow[t]{4}{*}{ Pseudomonas aeruginosa (50) } & M14659 & 0.10 & 0.20 & $\leq 0.05 \sim 3.13$ \\
\hline & Cefsulodin & 3.13 & 50 & $0.78 \sim>100$ \\
\hline & Cefoperazone & 6.25 & 100 & $0.39 \sim>100$ \\
\hline & Ceftazidime & 1.56 & 6.25 & $0.39 \sim 50$ \\
\hline
\end{tabular}

2 MIC of antibiotic that inhibited 50 and $90 \%$, respectively, of the isolates.

b Methicillin-resistant Staphylococcus aureus.

Inoculum size: $5 \times 10^{3} \mathrm{cfu}$.

Table 3. Antibacterial activities of M14659 and other cephalosporins against $\beta$-lactamase producing resistant strains of Pseudomonas aeruginosa.

\begin{tabular}{lccccc}
\hline \multirow{2}{*}{ Organism } & \multicolumn{5}{c}{ MIC $(\mu \mathrm{g} / \mathrm{m} 1)$} \\
\cline { 2 - 6 } & $\mathrm{M} 14659$ & $\mathrm{CTX}$ & $\mathrm{CFS}$ & $\mathrm{CPZ}$ & $\mathrm{CAZ}$ \\
\hline Pseudomonas aeruginosa $3 \mathrm{R}$ & 0.20 & $>100$ & $>100$ & $>100$ & 50 \\
P. aeruginosa 12R & 1.56 & $>100$ & 100 & $>100$ & 50 \\
P. aeruginosa 16R & 0.39 & $>100$ & 12.5 & 100 & 25 \\
\hline
\end{tabular}

Abbreviations: CTX; cefotaxime, CFS; cefsulodin, CPZ; cefoperazone, CAZ; ceftazidime. Inoculum size: $5 \times 10^{3} \mathrm{cfu}$.

at concentrations up to $100 \mu \mathrm{g} / \mathrm{ml}$. This finding suggests that M14659 may have potential for use against Enterobacter strains which are currently resistant to other cephalosporins.

M14659 is bactericidal at concentrations close to the MIC (Table 4). MBCs of both ceftazidime and M14659 were similar for three selected isolates. These preliminary findings indicate that M14659 
Table 4. MBCs and MICs of M14659 and ceftazidime.

\begin{tabular}{lcccccccc}
\hline \multirow{2}{*}{ Organism } & \multicolumn{3}{c}{ M14659 } & & \multicolumn{3}{c}{ Ceftazidime } \\
\cline { 2 - 3 } & $\begin{array}{c}\mathrm{MIC} \\
(\mu \mathrm{g} / \mathrm{ml})\end{array}$ & $\begin{array}{c}\mathrm{MBC} \\
(\mu \mathrm{g} / \mathrm{ml})\end{array}$ & $\begin{array}{c}\mathrm{MBC} / \\
\mathrm{MIC}\end{array}$ & & $\begin{array}{c}\mathrm{MIC} \\
(\mu \mathrm{g} / \mathrm{ml})\end{array}$ & $\begin{array}{c}\mathrm{MBC} \\
(\mu \mathrm{g} / \mathrm{ml})\end{array}$ & $\begin{array}{c}\mathrm{MBC} \\
\mathrm{MIC}\end{array}$ \\
\hline Staphylococcus aureus 209 $\mathrm{P}$ & 1.56 & 6.25 & 4 & & 6.25 & 12.5 & 2 \\
Escherichia coli NIHJ JC-2 & 0.20 & 0.20 & 1 & & 0.20 & 0.20 & 1 \\
Pseudomonas aeruginosa IFO 3445 & 0.78 & 1.56 & 2 & & 0.39 & 0.78 & 2 \\
\hline
\end{tabular}

MIC was determined by broth dilution method.

Inoculum size: $10^{4} \mathrm{cfu} / \mathrm{ml}$.

Table 5. Kinetics of hydrolysis of M14659 and other cephalosporins by $\beta$-lactamases obtained from various Gram-negative bacteria.

\begin{tabular}{|c|c|c|c|c|c|c|c|c|c|c|c|}
\hline \multirow{2}{*}{ Organism } & \multicolumn{5}{|c|}{$V \max ^{a}$} & \multicolumn{3}{|c|}{$K m\left(\mu_{\mathrm{M}}\right)$} & \multicolumn{3}{|c|}{$K i(\mu \mathrm{M})^{b}$} \\
\hline & CER & $\mathrm{NC}$ & M14659 & CTX & $\mathrm{CAZ}$ & CER & $\mathrm{NC}$ & CTX & M14659 & CTX & $\mathrm{CAZ}$ \\
\hline P. v. 1427 & 100 & 72 & $<0.1$ & 23 & $<0.1$ & 246 & 53 & 203 & 95 & NT & 4,010 \\
\hline E.c. & 100 & 240 & $<0.1$ & $<0.1$ & $<0.1$ & 482 & 220 & NT & 6.8 & 0.03 & 5.6 \\
\hline C.f. GN 7391 & 100 & 149 & $<0.1$ & $<0.1$ & $<0.1$ & 165 & 66 & NT & 0.24 & 0.0004 & 0.37 \\
\hline P.a. 3R & 100 & 1,157 & $<0.1$ & $<0.1$ & $<0.1$ & 307 & 273 & NT & 62 & 0.28 & 16 \\
\hline P. a. 12R & 100 & 2,050 & $<0.1$ & $<0.1$ & $<0.1$ & 76 & 216 & NT & 29 & 0.05 & 10 \\
\hline P. a. $16 \mathrm{R}$ & 100 & 2,524 & $<0.1$ & $<0.1$ & $<0.1$ & 77 & 299 & NT & 59 & 0.30 & 16 \\
\hline
\end{tabular}

Abbreviations: CER; Cephaloridine, NC; nitrocefin, CTX; cefotaxime, CAZ; ceftazidime, E.c.; Enterobacter cloacae, C.f.; Citrobacter freundii, P.v.; Proteus vulgaris, P.a.; Pseudomonas aeruginosa.

\& Rates of hydrolysis of antibiotics are expressed in percent hydrolysis of cephaloridine.

b $K i$ values were determined by using nitrocefin as a substrate.

NT: Not tested.

should be effective as a bactericidal agent.

\section{Kinetics of Hydrolysis}

M14659 was very stable to $\beta$-lactamases from $P$. vulgaris, $E$. cloacae, $C$. freundii and $P$. aeruginosa (Table 5); ceftazidime showed similar stability in terms of relative hydrolysis rates (Vmax) compared with the labile compounds cephaloridine and nitrocefin. M14659 was more stable than cefotaxime in the presence of $\beta$-lactamase from $P$. vulgaris. M14659 showed similar affinity to ceftazidime for enzymes from $E$. cloacae and $C$. freundii. $K i$ values $6.8 \mu \mathrm{M}$ and $0.24 \mu \mathrm{M}$ respectively compared with $5.6 \mu \mathrm{M}$ and $0.37 \mu \mathrm{M}$ for ceftazidime. In the presence of Pseudomonas $\beta$-lactamases, M14659 showed 2 to 4 -fold lower affinity compared with ceftazidime and at least 100 times lower affinity than cefotaxime.

\section{Inhibition of PBPs}

Affinities of M14659 and ceftazidime for PBPs are shown in Table 6. M14659 like ceftazidime inhibits PBP-3 preferentially at a similar $\mathrm{IC}_{50}$, approximately $0.2 \mu \mathrm{g} / \mathrm{ml}$, in E. coli. M14659 inhibited PBPs $1 \mathrm{~A}$ and $1 \mathrm{~B}$ of $E$. coli at lower concentrations than ceftazidime, 0.3 and $0.7 \mu \mathrm{g} / \mathrm{ml}$, respectively. Additionally M14659 acts at $12 \mu \mathrm{g} / \mathrm{ml}$ against PBP-2. This property may be of advantage as this PBP is an essential protein like PBP-3 in E. coli. Similarly in P. aeruginosa M14659 inhibited PBPs $1 \mathrm{~A}$ and $1 \mathrm{~B}$ at lower $\mathrm{IC}_{50} \mathrm{~s}$ than ceftazidime, 0.08 and $6.0 \mu \mathrm{g} / \mathrm{ml}$, respectively, and PBPs 3 and 4 at similar $\mathrm{IC}_{50}$ s to ceftazidime, 0.08 and $1.0 \mu \mathrm{g} / \mathrm{ml}$, respectively. 


\section{In Vivo Activity of M14659}

M14659 was effective in treating experimental septicaemia in mice following challenge with a range of Gram-positive and Gram-negative organisms (Table 7). S. aureus infections responded well, $\mathrm{ED}_{50}$ values for M14659 were comparable with those for cefazolin, and lower than those of cefotaxime

Table 6. Affinities of M14659 and ceftazidime for penicillin-binding proteins of Escherichia coli NIHJ JC-2 and Pseudomonas aeruginosa IFO 3445.

\begin{tabular}{|c|c|c|c|c|c|c|c|}
\hline \multirow{3}{*}{ Organism } & \multirow{3}{*}{ Antibiotic } & \multicolumn{6}{|c|}{$\mathrm{IC}_{50}(\mu \mathrm{g} / \mathrm{mI})$} \\
\hline & & \multicolumn{6}{|c|}{ Penicillin-binding proteins } \\
\hline & & $1 \mathrm{~A}$ & 1B & 2 & 3 & 4 & $5 / 6$ \\
\hline \multirow[t]{2}{*}{$\begin{array}{l}\text { E. coli } \\
\text { NIHJ JC-2 }\end{array}$} & M14659 & $\begin{array}{c}0.254 \\
(0.0011)\end{array}$ & $\begin{array}{c}0.673 \\
(0.0030)\end{array}$ & $\begin{array}{l}12.2 \\
(0.0545)\end{array}$ & $\begin{array}{c}0.272 \\
(0.0012)\end{array}$ & $\begin{array}{l}>224 \\
\quad(>1.0)\end{array}$ & $\begin{array}{l}>224 \\
\quad(>1.0)\end{array}$ \\
\hline & Ceftazidime & $\begin{array}{l}1.48 \\
(0.0085)\end{array}$ & $\begin{array}{l}9.46 \\
(0.0545)\end{array}$ & $\begin{array}{l}71.2 \\
(0.410)\end{array}$ & $\begin{array}{c}0.210 \\
(0.0012)\end{array}$ & $\begin{array}{l}>174 \\
(>1.0)\end{array}$ & $\begin{array}{l}>174 \\
>(1.0)\end{array}$ \\
\hline \multirow[t]{2}{*}{$\begin{array}{l}P . \text { aeruginosa } \\
\text { IFO } 3445\end{array}$} & M14659 & $\begin{array}{c}0.079 \\
(0.0011)\end{array}$ & $\begin{array}{c}5.99 \\
(0.0800)\end{array}$ & $\begin{array}{l}>74.8 \\
(>1.0)\end{array}$ & $\begin{array}{c}0.082 \\
(0.0011)\end{array}$ & $\begin{array}{c}0.973 \\
(0.0130)\end{array}$ & $\begin{array}{l}>74.8 \\
(>1.0)\end{array}$ \\
\hline & Ceftazidime & $\begin{array}{c}0.132 \\
(0.0023)\end{array}$ & $\begin{array}{l}13.9 \\
(0.240)\end{array}$ & $\begin{array}{l}>57.9 \\
(>1.0)\end{array}$ & $\begin{array}{c}0.061 \\
(0.0011)\end{array}$ & $\begin{array}{c}0.966 \\
(0.0167)\end{array}$ & $\begin{array}{l}>57.9 \\
(>1.0)\end{array}$ \\
\hline
\end{tabular}

The number in parentheses is a molar ratio to ${ }^{14} \mathrm{C}$-labeled benzylpenicilin required for $50 \%$ inhibition binding of labeled benzylpenicillin.

Table 7. In vivo antibacterial activities of M14659 and other cephalosporins against experimental systemic infections in mice.

\begin{tabular}{|c|c|c|c|}
\hline $\begin{array}{l}\text { Test organism (inoculum } \\
\text { size, cfu/mouse) }\end{array}$ & Antibiotic & $\begin{array}{l}\mathrm{MIC}^{\mathrm{b}} \\
(\mu \mathrm{g} / \mathrm{mI})\end{array}$ & $\begin{array}{c}\mathrm{ED}_{50} \\
(\mathrm{mg} / \mathrm{kg})\end{array}$ \\
\hline Staphylococcus aureus Smith & $\mathrm{M} 14659$ & 0.78 & 0.20 \\
\hline \multirow[t]{2}{*}{$\left(3.0 \times 10^{7}\right)$} & Cefazolin & 0.10 & 0.22 \\
\hline & Cefotaxime & 1.56 & 1.18 \\
\hline S. aureus No. 128 & M14659 & 1.56 & 1.59 \\
\hline \multirow[t]{3}{*}{$\left(1.5 \times 10^{8}\right)$} & Cefazolin & 0.39 & 1.35 \\
\hline & Cefotaxime & 1.56 & 5.48 \\
\hline & Ceftazidime & 6.25 & 20.6 \\
\hline $\operatorname{MRSA} 4^{\circ}$ & M14659 & 12.5 & 1.44 \\
\hline \multirow[t]{4}{*}{$\left(1.0 \times 10^{8}\right)$} & Cefazolin & 50 & 42.1 \\
\hline & Cefmetazole & 6.25 & 24.6 \\
\hline & Cefamandole & 6.25 & 11.8 \\
\hline & Cefotaxime & 25 & 18.4 \\
\hline MRSA 4-2 & M14659 & 50 & 2.98 \\
\hline \multirow[t]{5}{*}{$\left(1.0 \times 10^{8}\right)$} & Cefazolin & 100 & 75.8 \\
\hline & Cefmetazole & 25 & 29.8 \\
\hline & Cefamandole & 12.5 & 5.05 \\
\hline & Cefotaxime & 50 & 20.8 \\
\hline & Ceftazidime & $>100$ & $>100$ \\
\hline MRSA $58^{\circ}$ & M14659 & 12.5 & 9.79 \\
\hline \multirow[t]{3}{*}{$\left(1.0 \times 10^{7}\right)$} & Cefazolin & $>100$ & $>100$ \\
\hline & Cefmetazole & 25 & 54.8 \\
\hline & Cefamandole & 12.5 & 14.6 \\
\hline MRSA $242^{\circ}$ & M14659 & 100 & 2.04 \\
\hline \multirow[t]{4}{*}{$\left(1.5 \times 10^{8}\right)$} & Cefazolin & 100 & $>100$ \\
\hline & Cefamandole & 25 & 4.23 \\
\hline & Cefotaxime & 50 & $>100$ \\
\hline & Ceftazidime & 100 & $>100$ \\
\hline
\end{tabular}


Table 7. (Continued)

\begin{tabular}{|c|c|c|c|}
\hline $\begin{array}{l}\text { Test organism (inoculum } \\
\text { size, cfu/mouse) }\end{array}$ & Antibiotic & $\begin{array}{c}\mathrm{MIC}^{\mathrm{b}} \\
(\mu \mathrm{g} / \mathrm{ml})\end{array}$ & $\underset{(\mathrm{mg} / \mathrm{kg})}{\mathrm{ED}_{50}}$ \\
\hline Escherichia coli No. 67 & M14659 & 0.10 & 0.89 \\
\hline \multirow[t]{2}{*}{$\left(5.0 \times 10^{7}\right)$} & Cefotaxime & $<0.05$ & 2.83 \\
\hline & Ceftazidime & 0.10 & 4.63 \\
\hline E. coli No. 111 & M14659 & 0.10 & 1.73 \\
\hline \multirow[t]{2}{*}{$\left(1.0 \times 10^{5}\right)$} & Cefotaxime & $<0.05$ & 4.60 \\
\hline & Ceftazidime & 0.05 & 3.91 \\
\hline Klebsiella pneumoniae IFO 3317 & M14659 & $<0.05$ & 0.14 \\
\hline \multirow[t]{2}{*}{$\left(3.0 \times 10^{8}\right)$} & Cefotaxime & $<0.05$ & 2.35 \\
\hline & Ceftazidime & $<0.05$ & 1.59 \\
\hline Proteus mirabilis IFO 3849 & M14659 & $<0.05$ & 9.65 \\
\hline \multirow[t]{2}{*}{$\left(3.0 \times 10^{8}\right)$} & Cefotaxime & $<0.05$ & $>100$ \\
\hline & Ceftazidime & 0.10 & 18.8 \\
\hline P. vulgaris GN 5298 & M14659 & 0.20 & 0.16 \\
\hline \multirow[t]{2}{*}{$\left(7.0 \times 10^{4}\right)$} & Cefotaxime & 0.05 & 6.00 \\
\hline & Ceftazidime & 0.10 & 0.97 \\
\hline Enterobacter sp. No. 5 & M14659 & 0.78 & 0.10 \\
\hline \multirow[t]{2}{*}{$\left(1.0 \times 10^{7}\right)$} & Cefotaxime & 0.20 & 1.77 \\
\hline & Ceftazidime & 0.10 & 1.04 \\
\hline Enterobacter sp. No. 8 & M14659 & $<0.05$ & 1.04 \\
\hline \multirow[t]{2}{*}{$\left(8.4 \times 10^{7}\right)$} & Cefotaxime & $<0.05$ & $>30$ \\
\hline & Ceftazidime & 0.05 & 8.94 \\
\hline Citrobacter sp. No. 6 & M14659 & 0.10 & 0.09 \\
\hline \multirow[t]{2}{*}{$\left(1.0 \times 10^{7}\right)$} & Cefotaxime & 0.10 & 2.26 \\
\hline & Ceftazidime & 0.20 & 1.73 \\
\hline Citrobacter sp. No. 11 & M14659 & 1.56 & 0.13 \\
\hline \multirow[t]{2}{*}{$\left(3.0 \times 10^{7}\right)$} & Cefotaxime & 0.10 & 0.91 \\
\hline & Ceftazidime & 0.20 & 0.83 \\
\hline Serratia marcescens IFO 3736 & M14659 & 0.05 & 0.19 \\
\hline \multirow[t]{2}{*}{$\left(4.0 \times 10^{7}\right)$} & Cefotaxime & 0.10 & 42.4 \\
\hline & Ceftazidime & 0.10 & 1.73 \\
\hline S. marcescens IFO 3759 & M14659 & 0.05 & 3.68 \\
\hline \multirow[t]{2}{*}{$\left(4.0 \times 10^{7}\right)$} & Cefotaxime & 0.10 & 71.8 \\
\hline & Ceftazidime & 0.05 & 26.6 \\
\hline S. marcescens IFO 12648 & M14659 & 0.78 & 2.88 \\
\hline \multirow[t]{2}{*}{$\left(4.0 \times 10^{7}\right)$} & Cefotaxime & 0.39 & 78.4 \\
\hline & Ceftazidime & 0.20 & 42.3 \\
\hline Pseudomonas aeruginosa No. 3 & M14659 & 0.20 & 69.5 \\
\hline$\left(3.0 \times 10^{7}\right)$ & Ceftazidime & 25 & 240 \\
\hline P. aeruginosa No. 13 & M14659 & 1.56 & 48.9 \\
\hline$\left(1.0 \times 10^{7}\right)$ & Ceftazidime & 1.56 & 218 \\
\hline$P$. aeruginosa No. 19 & M14659 & 0.20 & 45.0 \\
\hline$\left(3.0 \times 10^{7}\right)$ & Ceftazidime & 1.56 & 238 \\
\hline P. aeruginosa No. 22 & M14659 & 0.39 & 51.1 \\
\hline$\left(4.0 \times 10^{7}\right)$ & Ceftazidime & 6.25 & 178 \\
\hline$P$. aeruginosa No. 34 & M14659 & 0.39 & 32.0 \\
\hline$\left(1.0 \times 10^{8}\right)$ & Ceftazidime & 1.56 & 170 \\
\hline$P$. aeruginosa No. 35 & M14659 & 0.20 & 64.8 \\
\hline$\left(1.0 \times 10^{7}\right)$ & Ceftazidime & 3.13 & 244 \\
\hline
\end{tabular}

a Mice were infected intraperitoneally with $0.2 \mathrm{ml}$ of a bacterial suspension in saline containing $5 \%$ gastric mucin.

b Inoculum size: $5 \times 10^{3} \mathrm{cfu}$.

c Methicillin-resistant Staphylococcus aureus. 
Table 8. Binding of M14659 and ceftazidime to serum proteins of different animal species.

\begin{tabular}{lcrr}
\hline $\begin{array}{c}\text { Species of } \\
\text { animal }\end{array}$ & $\begin{array}{c}\text { Antibiotic } \\
\text { concentrations } \\
(\mu \mathrm{g} / \mathrm{ml})\end{array}$ & \multicolumn{2}{c}{ Serum binding $(\%)$} \\
\hline Human & 100 & $90.8 \pm 0.5$ & $\mathrm{CAZ}$ \\
Mouse & 100 & $63.0 \pm 0.9$ & $25.5 \pm 3.7$ \\
Rat & 100 & $95.4 \pm 0.1$ & $4.2 \pm 1.4$ \\
\hline
\end{tabular}

CAZ: Ceftazidime.

Results are given as means $\pm \mathrm{SE}$ of 3 tests.

Table 9. Plasma concentrations and half-lives of M14659 and ceftazidime after single $20-\mathrm{mg} / \mathrm{kg}$ iv injections in mice.

\begin{tabular}{|c|c|c|c|c|}
\hline \multirow{2}{*}{ Parameter } & \multirow{2}{*}{$\underset{\text { (minutes) }}{\text { Time }}$} & \multicolumn{2}{|c|}{ Bioassay } & \multirow{2}{*}{$\frac{\text { HPLC }}{\text { M14659 }}$} \\
\hline & & M14659 & Ceftazidime & \\
\hline Plasma & 1 & $113.2 \pm 23.8$ & $47.1 \pm 6.0$ & $101.1 \pm 10.6$ \\
\hline concentration & 2.5 & $43.8 \pm 7.3$ & $52.3 \pm 7.1$ & $58.8 \pm 7.1$ \\
\hline \multirow[t]{8}{*}{$(\mu \mathrm{g} / \mathrm{ml})$} & 5 & $28.2 \pm 2.7$ & $26.6 \pm 4.8$ & $48.4 \pm 1.0$ \\
\hline & 10 & $23.0 \pm 1.2$ & $17.3 \pm 0.7$ & $33.4 \pm 2.3$ \\
\hline & 20 & $19.2 \pm 1.0$ & $8.7 \pm 1.8$ & $21.1 \pm 1.3$ \\
\hline & 30 & $15.3 \pm 3.8$ & $4.1 \pm 0.3$ & $17.3 \pm 1.3$ \\
\hline & 40 & $12.7 \pm 2.1$ & $2.4 \pm 0.1$ & $11.7 \pm 0.3$ \\
\hline & 60 & $7.6 \pm 1.0$ & $1.2 \pm 0.1$ & $8.6 \pm 0.7$ \\
\hline & 120 & $1.3 \pm 0.1$ & $\mathrm{ND}$ & $2.0 \pm 0.8$ \\
\hline & 240 & ND & ND & $0.4 \pm 0.3$ \\
\hline $\mathrm{T}_{1 / 2}(\alpha)^{\mathrm{a}}$ (minutes) & & 0.6 & ND & 3.0 \\
\hline $\mathrm{T}_{1 / 2}(\beta)^{\mathrm{b}}$ (minutes) & & 26.3 & 10.6 & 29.6 \\
\hline AUC $(\mu \mathrm{g} \cdot$ minutes $/ \mathrm{ml})$ & & 1,386 & 569 & 1,725 \\
\hline $\mathrm{CL}_{\text {tot }}(\mathrm{ml} / \mathrm{minute} / \mathrm{kg})$ & & 14.4 & 35.1 & 11.6 \\
\hline
\end{tabular}

Results are given as means \pm SE for 5 mice.

ND: Not detected.

a Plasma half-life at $\alpha$ phase.

b Plasma half-life at $\beta$ phase.

and ceftazidime. Some response to M14659 was also seen in infections due to methicillin-resistant Staphylococci (MRSA), though its MICs were relatively high; $\mathrm{ED}_{50}$ values of M14659 ranged from 1.44 to $9.79 \mathrm{mg} / \mathrm{kg}$, and were lower than those of cefazolin, cefmetazole, cefamandole, cefotaxime or ceftazidime. Even in the infection due to MRSA 4-2, which has been isolated from MRSA 4 as a single colony by using an agar plate containing $25 \mu \mathrm{g}$ of cefazolin per $\mathrm{ml}$ after the culture at $44^{\circ} \mathrm{C}$ for 8 hours to eliminate penicillinase-encoding plasmids and induces PBP-2', M14659 was more active than the comparative compounds. Therefore, the activity of M14659 to the MRSA infections seemed to be attributable not to the heterogenicity of the isolates but to its activity in vivo.

Pseudomonas infections responded at $\mathrm{ED}_{50} \mathrm{~s}$ in the range 32 to $69.5 \mathrm{mg} / \mathrm{kg} \mathrm{M} 14659$; ceftazidime was 3 to 5 -fold less active than M14659.

M14659 was as effective as ceftazidime in protection tests using E. coli and Proteus species, and more active than ceftazidime against Klebsiella pneumoniae and Serratia marcescens. Two Enterobacter infections were more susceptible to M14659 than to cefotaxime or ceftazidime. This finding correlates with the low affinity of M14659 for Enterobacter $\beta$-lactamase and the narrow MIC range observed for clinical isolates. Citrobacter strains which produce a similar chromosomal $\beta$-lactamase were also effectively eradicated in experimental infections. 
Table 10. Urinary excretion of M14659 and ceftazidime after single $20-\mathrm{mg} / \mathrm{kg}$ iv injections in mice.

\begin{tabular}{|c|c|c|c|}
\hline \multirow{3}{*}{$\begin{array}{l}\text { Time } \\
\text { (hours) }\end{array}$} & \multicolumn{3}{|c|}{ Recovery rate $(\%)$} \\
\hline & \multicolumn{2}{|c|}{ Bioassay } & \multirow{2}{*}{$\frac{\text { HPLC }}{\text { M14659 }}$} \\
\hline & M14659 & Ceftazidime & \\
\hline $0 \sim 3$ & $42.0 \pm 8.8$ & $49.6 \pm 9.4$ & $47.5 \pm 6.2$ \\
\hline $3 \sim 6$ & $23.3 \pm 8.7$ & $20.7 \pm 7.1$ & $16.9 \pm 3.8$ \\
\hline $6 \sim 9$ & $1.6 \pm 0.7$ & $3.2 \pm 2.0$ & $2.6 \pm 2.1$ \\
\hline $9 \sim 24$ & $1.0 \pm 0.4$ & $0.6 \pm 0.1$ & ND \\
\hline $0 \sim 24$ & $67.8 \pm 3.2$ & $74.2 \pm 5.0$ & $67.0 \pm 2.0$ \\
\hline
\end{tabular}

Results are given as means \pm SE for 10 mice.

ND: Not detected.

\section{Serum Protein Binding of M14659}

The percentages of binding of M14659 to human, mouse and rat serum were $90.8,63.0$ and $95.4 \%$, respectively. Corresponding values for ceftazidime to the respective sera were $25.5,4.2$ and $12.0 \%$, respectively. Thus, M14659 was highly bound to the serum proteins of humans, mice and rats as compared with ceftazidime (Table 8).

\section{Plasma Concentrations of M14659}

After intravenous administration plasma concentrations of M14659 in mice were markedly higher than those of ceftazidime (Table 9), and M14659 was still detected at a concentration of $1.3 \mu \mathrm{g} / \mathrm{ml}$ by bioassay and $2.0 \mu \mathrm{g} / \mathrm{ml}$ by HPLC in mouse plasma 120 minutes after administration, when ceftazidime was not detected. Further, the plasma half-lives of M14659 were 0.6 minute at $\alpha$ phase and 26.3 minutes at $\beta$ phase by bioassay, and 3.0 and 29.6 minutes by HPLC, respectively. AUC and $\mathrm{CL}_{\text {tos }}$ of M14659 were $1,386 \mu \mathrm{g} \cdot$ minutes $/ \mathrm{ml}$ and $14.4 \mathrm{ml} / \mathrm{minute} / \mathrm{kg}$ by bioassay, and $1,725 \mu \mathrm{g} \cdot$ minutes/ $\mathrm{ml}$ and $11.6 \mathrm{ml} / \mathrm{minute} / \mathrm{kg}$ by HPLC, respectively. An $\alpha$ phase was not observed with ceftazidime, and the plasma half-life at $\beta$ phase was 10.6 minutes by bioassay. $A U C$ and $C_{\text {tot }}$ of ceftazidime were $569 \mu \mathrm{g} \cdot$ minutes $/ \mathrm{ml}$ and $35.1 \mathrm{ml} / \mathrm{minute} / \mathrm{kg}$ by bioassay (Table 9 ).

\section{Urinary Concentrations of M14659}

Recovery of M14659 in mouse urine collected at 0 to 24 hours after administration was $67.8 \%$ by bioassay, and $67.0 \%$ by HPLC. The recovery of ceftazidime was $74.2 \%$ by bioassay (Table 10 ).

\section{Discussion}

A number of anti-pseudomonal cephalosporins like ceftazidime has been developed as alternative treatments for serious pseudomonal infections which have been traditionally treated with aminoglycosides alone or in combination with $\beta$-lactam antibiotics. Although ceftazidime is reported to be the most potent anti-pseudomonal agent among currently clinically used cephalosporins ${ }^{17}$, it is also true that its anti-staphylococcal activity is poor ${ }^{1)}$. Further, some clinical isolates of $P$. aeruginosa resistant to ceftazidime have already been reported ${ }^{3,4}$. Our search for a new cephalosporin with a balanced spectrum of activity and more potent anti-pseudomonal activity than ceftazidime has resulted in the development of M14659.

M14659 has a broad antibacterial spectrum covering Gram-positive and Gram-negative bacteria, similar to that exhibited by cefotaxime and ceftazidime. M14659 was more active in vitro than ceftazidime against clinical isolates of $S$. aureus including methicillin-resistant strains, and equipotent to ceftazidime against Gram-negative isolates excepting $P$. aeruginosa. Against clinical isolates of $P$. aeruginosa, M14659 was superior to anti-pseudomonal cephalosporins such as cefsulodin, cefoper- 
azone and ceftazidime. Generally, $P_{\text {seudomonas }}$ species are known to be resistant to $\beta$-lactam antibiotics via three possible mechanisms ${ }^{4\rangle}$ : (1) Production of chromosomal or plasmid mediated $\beta$-lactamases, (2) altered permeability to $\beta$-lactam antibiotics, or (3) altered penicillin-binding proteins. Mechanism (3), however, is thought to be infrequent ${ }^{4}$. Our study using $\beta$-lactamase producing strains of $P$. aeruginosa, which are thought to be resistant to cefsulodin, cefoperazone and ceftazidime mainly via mechanism (1) or both (1) and (2), indicated that M14659 was also active against resistant strains of $P$. aeruginosa, and M14659 was very stable to the $\beta$-lactamases obtained from the strains. Further, the affinities of M14659 for the $\beta$-lactamases, which were expressed as $K i$ values, were lower than those of cefotaxime and ceftazidime. Recently, it has been proposed that the tight binding of non-hydrolyzable cephems by periplasmic $\beta$-lactamase molecules, i.e., trapping, could prevent them from binding to target PBPs and create the resistance seen in certain strains of bacteria such as Enterobacter, Serratia, and Pseudomonas ${ }^{11,12}$. If this theory is true, the excellent activity of M14659 against the $\beta$-lactamase producing resistant strains of $P$. aeruginosa may be attributable to its low affinity for their chromosomal $\beta$-lactamase. Furthermore, M14659 showed greater affinity than ceftazidime for PBP$1 \mathrm{~A}$ and PBP-1B of $E$. coli and $P$. aeruginosa. Both these factors may be important in the bactericidal activity of M14659 and its activity against $P$. aeruginosa which are resistant to other so-called thirdgeneration cephalosporins.

In vivo activity of M14659 against experimental systemic infections due to $S$. aureus including methicillin-resistant strains was superior to that of cefotaxime or ceftazidime. Against infections due to Gram-negative bacteria except $P$. aeruginosa, M14659 was 3 to 220 times more active than cefotaxime and 2 to 20 times than ceftazidime on the basis of $\mathrm{ED}_{50}$ values, though MICs of M14659 against the challenge strains were similar to or higher than those of cefotaxime and ceftazidime. Furthermore, its in vivo activity against $P$. aeruginosa was marginally superior to that of ceftazidime, probably mainly reffecting the higher in vitro activity of the compound. Against the other test organisms M14659 showed a more potent therapeutic effect than might be expected in comparison of its MICs with those of ceftazidime. This might be explained by more advantageous pharmacokinetic properties of the former compound. M14659 was found more highly bound to human, mouse and rat serum proteins than ceftazidime. Plasma half-life of M14659 in mice was, however, much longer than that of ceftazidime, and M14659 at a concentration thought to inhibit many Gram-negative bacteria was still detected in mouse plasma 120 minutes after an intravenous dose of $20 \mathrm{mg} / \mathrm{kg}$ of the compound, similar to what has been reported for ceftriaxone ${ }^{13)}$. However, the urinary excretion of M14659 in mice was as high as that of ceftazidime. These results suggest that M14659 is a long-acting compound similar to ceftriaxone, and these characteristics may contribute to the excellent therapeutic properties of M14659. However, since several $\beta$-lactam antibiotics have been reported to show strong in vivo activities because of their (i) synergism with serum factors ${ }^{14}$, (ii) facilitation of phagocytosis of neutrophils through antibiotic action on bacteria $\left.{ }^{15}, 10\right)$, or (iii) activation of phagocyte functions ${ }^{17}$, further studies on participation of these factors may be required to explain the good therapeutic effect of M14659 more fully.

In conclusion, these findings indicate that M14659 is a novel anti-pseudomonal cephalosporin which has a balanced spectrum of activity and promising therapeutic activity in experimental infections in mice. If preliminary findings are borne out in man, M14659 has considerable potential for the treatment of a wide range of infections and may be a valuable alternative to currentily available anti-pseudomonal cephalosporins.

\section{Experimental}

NMR spectra were determined with a Jeol FX-90Q spectrometer. IR spectra were recorded on a Nicolet 5DX spectrometer. Optical rotation was measured with a Jasco DIP-181 polarimeter.

2-(2-Triphenylmethylamino-4-thiazolyl)-2-[ $Z$-[diphenylmethyloxycarbonyl(3,4-diacetoxyphenyl)methyl]oxyimino]acetic Acid (Compound 1)

Thionyl chloride $(60 \mathrm{ml})$ was added to a suspension of (3,4-diacetoxyphenyl)acetic acid $(51.1 \mathrm{~g})$ in $105 \mathrm{ml}$ of $\mathrm{CCl}_{4}$, and the mixture was heated at $70^{\circ} \mathrm{C}$ for 1 hour. After cooling to room temp, $N$ - 
bromosuccinimide $(42.3 \mathrm{~g}), \mathrm{CCl}_{4}(105 \mathrm{ml})$ and a little amount of $\mathrm{HBr}$ were added, and the mixture was heated for an additional 1 hour. The resulting mixture was concentrated under reduced pressure, and the residue was redissolved in $\mathrm{CCl}_{4}$. After filtering off insoluble material, the filtrate was dissolved in $400 \mathrm{ml}$ of $\mathrm{Me}_{2} \mathrm{CO}$ and the $\mathrm{pH}$ of the soln was adjusted to 4.0 with satd $\mathrm{NaHCO}_{3}$ aq soln under ice-cooling. The resulting mixture was extracted with $\mathrm{CHCl}_{3}$. The $\mathrm{CHCl}_{3}$ layer was washed with satd $\mathrm{NaCl}$ aq soln and dried over anhydrous $\mathrm{Na}_{2} \mathrm{SO}_{4}$. The dried soln was concentrated under reduced pressure to give $61.4 \mathrm{~g}$ of 2-bromo-2-(3,4-diacetoxyphenyl)acetic acid (I). Then, diphenyldiazomethane $(39.6 \mathrm{~g})$ was added to a soln of the product $\mathrm{I}(61.4 \mathrm{~g})$ in $500 \mathrm{ml}$ of $\mathrm{Me}_{2} \mathrm{CO}$, and the soln was stirred at room temp for 1 hour. The resulting soln was concentrated under reduced pressure and the residue was purified by silica gel column chromatography to give $48.4 \mathrm{~g}$ of diphenylmethyl 2-bromo-2-(3,4diacetoxyphenyl)acetate (II). The product II $(48.4 \mathrm{~g})$ in $200 \mathrm{ml}$ of $\mathrm{MeCN}$ and $\mathrm{Et}_{3} \mathrm{~N}(13.6 \mathrm{ml})$ were added to an ice-cooled suspension of $N$-hydroxyphthalimide $(15.9 \mathrm{~g})$ in $300 \mathrm{ml}$ of MeCN. The mixture was stirred under ice-cooling for 1.5 hours. The resulting soln was concentrated under reduced pressure and redissolved in EtOAc. The soln was washed with $\mathrm{H}_{2} \mathrm{O}, 1 \mathrm{~N}$ citric acid soln and with satd $\mathrm{NaCl}$ aq soln in that order. The washed soln was dried over anhydrous $\mathrm{Na}_{2} \mathrm{SO}_{4}$ and concentrated under reduced pressure, and the residue was purified by silica gel column chromatography to give $15.3 \mathrm{~g}$ of diphenylmethyl 2-phthalimidooxy-2-(3,4-diacetoxyphenyl)acetate (III). To a soln of the product $\mathrm{III}(15.3 \mathrm{~g})$ in $200 \mathrm{ml}$ of $\mathrm{CH}_{2} \mathrm{Cl}_{2}$, methylhydrazine $(1.34 \mathrm{ml})$ was slowly added at $-60^{\circ} \mathrm{C}$, and the mixture was allowed to stand until room temp was reached. After stirring for 2 hours, methylhydrazine $(0.07 \mathrm{ml})$ was added to the mixture, followed by stirring for an additional 30 minutes. The insoluble material was filtered off, the filtrate was concentrated under reduced pressure, and the residue was purified by silica gel column chromatography to give $8.7 \mathrm{~g}$ of diphenylmethyl 2-aminooxy-(3,4diacetoxyphenyl)acetate (IV). A soln of the product IV (8.7 g) in $150 \mathrm{ml}$ of MeOH was added dropwise to a soln of (2-triphenylmethylamino-4-thiazolyl)glyoxylic acid $(7.62 \mathrm{~g})$ in $400 \mathrm{ml}$ of $\mathrm{MeOH}$. The mixture was stirred at room temp for 1.5 hours, and concentrated under reduced pressure to give $16.0 \mathrm{~g}$ of the objective compound 1: IR $(\mathrm{KBr}) \mathrm{cm}^{-1} 1772,1256,1209,1180,754,701 ;{ }^{1} \mathrm{H} \mathrm{NMR}\left(\mathrm{CDCl}_{3}\right)$ $\delta 8.9(1 \mathrm{H}, \mathrm{s}), 7.8 \sim 7.2(28 \mathrm{H}, \mathrm{m}), 6.9(1 \mathrm{H}, \mathrm{s}), 6.8(1 \mathrm{H}, \mathrm{s}), 5.9(1 \mathrm{H}, \mathrm{s}), 2.3(6 \mathrm{H}, \mathrm{s})$.

Diphenylmethyl $(6 R, 7 R)-7-[2-(2-$ Triphenylmethylamino-4-thiazolyl)-2-[ $Z$-[( $S)$-diphenylmethyloxycarbonyl(3,4-diacetoxyphenyl)methyl]oxyimino]acetamido]-3-[(2-diphenylmethyloxycarbonyl-5-methyls-triazolo[1,5-a]pyrimidin-7-yl)thiomethyl]-8-oxo-5-thia-1-azabicyclo[4.2.0]oct-2-ene-2-carboxylate (Compound 2)

To an ice-cooled soln of the compound $1(5.6 \mathrm{~g})$ and diphenylmethyl $(6 R, 7 R)-7$-amino-3-[( $2 \mathrm{di}-$ phenylmethyloxycarbonyl-5-methyl-s-triazolo[1,5-a]pyrimidin-7-yl)thiomethyl]-8-oxo-5-thia-1-azabicyclo[4.2.0]oct-2-ene-2-carboxylate ${ }^{18)}(5.0 \mathrm{~g})$ in $170 \mathrm{ml}$ of $\mathrm{CH}_{2} \mathrm{Cl}_{2}, 1.4 \mathrm{~g}$ of dicyclohexylcarbodiimide was added, and the mixture was stirred at room temp for 5 hours. After filtering off the insoluble material, the filtrate was concentrated under reduced pressure. The residue was dissolved in EtOAc and the material was filtered off. The filtrate was washed with satd $\mathrm{NaCl}$ aq soln and dried over anhydrous $\mathrm{Na}_{2} \mathrm{SO}_{4}$. The dried soln was concentrated under reduced pressure, and the residue was purified by silica gel column chromatography to give $0.73 \mathrm{~g}$ of the objective compound 2 : $\mathrm{IR}(\mathrm{KBr})$ $\mathrm{cm}^{-1} 1780,1742,1737,1507,1249,1205,1182,700 ;{ }^{1} \mathrm{H}$ NMR (DMSO- $\left.d_{8}\right) \delta 9.7(1 \mathrm{H}, \mathrm{d}, J=8 \mathrm{~Hz}), 8.9$ $(1 \mathrm{H}, \mathrm{br} \mathrm{s}), 7.5 \sim 7.1(50 \mathrm{H}, \mathrm{m}), 6.9(1 \mathrm{H}, \mathrm{s}), 6.82(1 \mathrm{H}, \mathrm{s}), 6.78(1 \mathrm{H}, \mathrm{s}), 5.9(1 \mathrm{H}, \mathrm{s}), 5.8(1 \mathrm{H}, \mathrm{dd}, J=4$ and $8 \mathrm{~Hz}), 5.2(1 \mathrm{H}, \mathrm{d}, J=4 \mathrm{~Hz}), 4.3(2 \mathrm{H}, \mathrm{br} \mathrm{s}), 3.6(2 \mathrm{H}, \mathrm{ABq}), 2.6(3 \mathrm{H}, \mathrm{s}), 2.2(6 \mathrm{H}, \mathrm{s})$.

$(6 R, 7 R)-7-[2-(2-$ Amino-4-thiazoly1) -2-[Z-[(S)-carboxy(3,4-dihydroxypheny1)methyl]oxyimino]acetamino]-3-[(2-carboxy-5-methyl-s-triazolo[1,5-a]pyrimidin-7-yl)thiomethyl]-8-oxo-5-thia-1-azabicyclo [4.2.0]oct-2-ene-2-carboxylic Acid Sodium Salt (M14659, Compound 3)

To a soln of the compound $2(0.73 \mathrm{~g})$ in $3 \mathrm{ml}$ of $\mathrm{ClCH}_{2} \mathrm{CH}_{2} \mathrm{Cl}$, anisole $(0.4 \mathrm{ml})$ and $\mathrm{CF}_{3} \mathrm{COOH}$ $(0.8 \mathrm{ml})$ were added under ice-cooling, and the resulting soln was stirred at room temp for 3 hours. Additional $\mathrm{CF}_{3} \mathrm{COOH}(0.6 \mathrm{ml})$ was added and the mixture was stirred for another 30 minutes. After removing the solvent by decantation, the residue was washed with $\mathrm{ClCH}_{2} \mathrm{CH}_{2} \mathrm{Cl}$ and crystallized with $\mathrm{Et}_{2} \mathrm{O}$ to give $0.3 \mathrm{~g}$ of the product $\mathbf{V}$. The product $\mathbf{V}(0.27 \mathrm{~g})$ was suspended in $11 \mathrm{ml} \mathrm{of} \mathrm{H}_{2} \mathrm{O}$, and the 
$\mathrm{pH}$ of the mixture was adjusted to 8.0 with $\mathrm{NaHCO}_{3}$. After stirring at room temp for 6 hours, the resulting soln was applied to a Diaion HP-10 column. The appropriate fractions eluted with $\mathrm{H}_{2} \mathrm{O}$ were collected and lyophilized to give $0.14 \mathrm{~g}$ of M14659: $\mathrm{IR}(\mathrm{KBr}) \mathrm{cm}^{-1} 1763,1599,1514,1474,1404,1360$, 1314; ${ }^{1} \mathrm{H}$ NMR $\left(\mathrm{D}_{2} \mathrm{O}\right) \delta 7.2(1 \mathrm{H}, \mathrm{s}), 7.0 \sim 6.8(4 \mathrm{H}, \mathrm{m}), 5.7(1 \mathrm{H}, \mathrm{d}, J=5 \mathrm{~Hz}), 5.4(1 \mathrm{H}, \mathrm{s}), 5.0(1 \mathrm{H}, \mathrm{d}$, $J=5 \mathrm{~Hz}), 4.3(2 \mathrm{H}, \mathrm{ABq}), 3.4(2 \mathrm{H}, \mathrm{ABq}), 2.6(3 \mathrm{H}, \mathrm{s}) ;[\alpha]_{\mathrm{D}}^{25}+27.4^{\circ}\left(c 1.0, \mathrm{H}_{2} \mathrm{O}\right)$.

Acknowledgment

The authors are grateful to Dr. M. TAJima of Sankyo Co., Ltd., Tokyo, Japan, for his gifts of $\beta$-lactamases obtained from Citrobacter freundii GN 7391 and Proteus vulgaris 1427.

\section{References}

1) Garzone, P.; J. Lyon \& V.L. YU: Third-generation and investigational cephalosporins: II. Microbiologic review and clinical summaries. Drug Intell. Clin. Pharm. 17: 615 622, 1983

2) Rolston, K. V. I.; P. H. Chandrasekar, J. L. LeFrock \& R. F. Schell: The activity of ceftazidime, other $\beta$-lactams, and aminoglycosides against Pseudomonas aeruginosa. Chemotherapy (Basel) 30: $31 \sim$ 34,1984

3) Rolston, K.; M. E. Alvarez, J. F. Hoy, B. LeBlanc, D. H. Ho \& G. P. Bodey: Comparative in vitro activity of cefpirome and other antimicrobial agents against isolates from cancer patients. Chemotherapy (Basel) 32: 344 351, 1986

4) PrInce, A.: Antibiotic resistance of Pseudomonas species. J. Pediatr. 108: 830 834, 1986

5) Mochizuki, H.; H. Inaba, M. Mizota, K. Kato, H. Kosuzume, H. Tajima, H. Onishi \& E. Mochida: Antibacterial evaluation of M14646, M14648 \& M14659, new semisynthetic cephalosporins. Program and Abstracts of the 25th Intersci. Conf. on Antimicrob. Agents Chemother., No. 356, p. 156, Minneapolis, Sept. 2 Oct. 2, 1985

6) Minami, S.; A. Yotsuit, M. Inoue \& S. Mitsuhashi: Induction of $\beta$-lactamase by various $\beta$-lactam antibiotics in Enterobacter cloacae. Antimicrob. Agents Chemother. 18: 382 385, 1980

7) Ross, G.W. \& C. H. O'Callaghan: $\beta$-Lactamase assays. In Methods in Enzymology. Volume 43. Antibiotics. Ed., J. H. HASH, pp. 69 85, Academic Press, New York, 1975

8) Spratt, B. G.: Properties of the penicillin-binding proteins of Escherichia coli K-12. Eur. J. Biochem. 72: $341 \sim 352,1977$

9) Noguchi, H.; M. Matsuhashi \& S. Mitsuhashi: Comparative studies of penicillin-binding proteins in Pseudomonas aeruginosa and Escherichia coli. Eur. J. Biochem. 100: 41 49, 1979

10) Litchfield, J. T. \& F. WilcoXon: A simplified method of evaluating dose-effect experiments. J. Pharmacol. Exp. Ther. 96: 99 113, 1949

11) SANDERs, C. C.: Novel resistance selected by the new expanded-spectrum cephalosporins: A concern. J. Infect. Dis. 147: 585 589, 1983

12) Then, R. L. \& P. ANGEHRN: Trapping of nonhydrolyzable cephalosporins by cephalosporinases in Enterobacter cloacae and Pseudomonas aeruginosa as a possible resistance mechanism. Antimicrob. Agents Chemother. 21: 711 717, 1982

13) Angehrn, P.; P. J. Probst, R. Reiner \& R. L. Then: Ro 13-9904, a long-acting broad-spectrum cephalosporin: In vitro and in vivo studies. Antimicrob. Agents Chemother. 18: 913 921, 1980

14) Okumura, K.; T. YокотA, H. Kato \& H. Tsurr: Effects of cefuroxime and other cephalosporins on opsonification of serum and phagocytosis of polymorphonuclear leukocytes to E. coli. Chemotherapy (Tokyo) 27 (S-6): 76 82, 1979

15) Petit, J. C. \& G. L. DAguest: Enhanced killing of Pseudomonas aeruginosa by human polymorphonuclear leukocytes in presence of subinhibitory concentrations of carbenicillin and ticarcillin. Biomedicine 34: $29 \sim 33,1981$

16) Watanabe, Y.; S. Tawara, Y. Mine, H. Kikuchi, S. Goto \& S. Kuwahara: Synergism of cephalosporins at subinhibitory concentrations and polymorphonuclear leukocytes on phagocytic killing of Escherichia coli and its mode of action. J. Antibiotics 39:294 303, 1986

17) Ohnishi, H.; H. Kosuzume, H. Inaba, M. Okura, H. Mochizuki, Y. Suzuki \& R. Fuji: Effects of AC1370, a new semisynthetic cephalosporin, on phagocyte functions. Antimicrob. Agents Chemother. 23: $874 \sim 880,1983$

18) Ohnishi, H.; K. Kosuzume, M. Mtzota, Y. Suzuki \& E. Mochida (Mochida Pharm.): Cephalosporin derivatives. Jpn. Kokai 126089('86), June 13, 1986 